University of Wollongong

Research Online

Faculty of Engineering and Information

Faculty of Engineering and Information

Sciences - Papers: Part A

Sciences

$1-1-2013$

\title{
Helpfulness of online product reviews as seen by consumers: source and content features
}

Mengxiang Li

University of Wollongong, mli@uow.edu.au

Liqiang Huang

Zhejiang University

Chuan-Hoo Tan

City University, tancho@comp.nus.edu.sg

Kwok-Kee Wei

City University, isweikk@cityu.edu.hk

Follow this and additional works at: https://ro.uow.edu.au/eispapers

Part of the Engineering Commons, and the Science and Technology Studies Commons

Research Online is the open access institutional repository for the University of Wollongong. For further information contact the UOW Library: research-pubs@uow.edu.au 


\title{
Helpfulness of online product reviews as seen by consumers: source and content features
}

\begin{abstract}
Online product reviews are important determinants of consumers' purchase decision. Although prior research has articulated various benefits of online product reviews, there are few investigations into whether or not they are perceived as helpful by consumers. Product review helpfulness is conceptualized as a second-order formative construct, which is manifested by perceived source credibility, perceived content diagnosticity, and perceived vicarious expression of the product review. In this study, we conduct a laboratory experiment to investigate product review helpfulness as well as its corresponding antecedents from the product review feature perspective (i.e., source- and content-based review features). Findings from the study are threefold. First, the results of the data analysis support the theoretical conceptualization of product review helpfulness as a formative construct. Second, the results support the notion that the source- and content-based review features have direct impact on product review helpfulness. Consumers perceive customer-written product reviews as more helpful than those written by experts; they also perceive a concrete review as more helpful than an abstract review. Third, we find an interaction effect of the source- and content-based features of product reviews on review helpfulness. A customer-written product review with a low level of content abstractness yields the highest perceived review helpfulness.
\end{abstract}

\section{Keywords}

online, product, features, reviews, helpfulness, seen, consumers, source, content

\section{Disciplines}

Engineering | Science and Technology Studies

\section{Publication Details}

Li, M., Huang, L., Tan, C. \& Wei, K. (2013). Helpfulness of online product reviews as seen by consumers: source and content features. International Journal of Electronic Commerce, 17 (4), 101-136. 


\section{Helpfulness of Online Product Reviews as Seen by Consumers: Source and Content Features}

\section{Mengxiang Li (First author)}

Ph.D. Candidate, Department of Information Systems, College of Business, City University of Hong Kong, Tat Chee Avenue, Kowloon, Hong Kong, P.R.C, China

Tel: +852-3442-5202 / E-mail: mengxiali2@student.cityu.edu.hk

\section{Liqiang Huang (Co-first author and corresponding author) ${ }^{1}$}

Ph.D. Candidate, Depart of Information Systems, The University of Science and Technology of China \& City University of Hong Kong Joint Advanced Research Center, Suzhou, China

Tel: +852-6249-0347 / E-mail: hlq@mail.ustc.edu.cn

\section{Chuan-Hoo Tan}

Assistant Professor, Department of Information Systems, College of Business, City University of Hong Kong, Tat Chee Avenue, Kowloon, Hong Kong, P.R.C, China

Tel: +852-3442-9720 / E-mail: ch.tan@cityu.edu.hk

\section{Kwok-Kee Wei}

Chair Professor, Department of Information Systems, College of Business, City University of Hong Kong, Tat Chee Avenue, Kowloon, Hong Kong, P.R.C, China

Tel: +852-3442-9590 / E-mail: isweikk@cityu.edu.hk

Mengxiang Li (mengxiali2@student.cityu.edu.hk) is a Ph.D. Candidate of Information Systems at City University of Hong Kong. His articles have appeared in premium information system conferences, such as International Conference on Information Systems and Pacific Asia Conference on Information Systems, as well as leading journal such as Decision Support Systems. His current research interests include the electronic commerce, design and evaluation of consumer-based decision support interfaces, mobile commerce and NeuroIS.

Liqiang Huang (hlq@mail.ustc.edu.cn) is a Ph.D. Candidate of Information Systems, at The University of Science and Technology of China \& City University of Hong Kong Joint

${ }^{1}$ Both of the first two authors are joint first authors and, they contributed equally to this work. 
Advanced Research Center. His work has appeared in premium information system conferences such as International Conference on Information Systems and Pacific Asia Conference on Information Systems. His current research interests include the electronic commerce, mobile commerce, and electronic marketing.

Chuan-Hoo Tan (ch.tan@cityu.edu.hk) is currently an Assistant Professor of information systems at City University of Hong Kong, Hong Kong. His research interests include the design and evaluation of consumer-based decision support interfaces, electronic commerce, as well as IT usage in formal and informal organizations. He has authored or coauthored in top-tier information systems journals, such as MIS Quarterly, Information Systems Research, Journal of Management Information Systems, Decision Support Systems and IEEE Transactions on Engineering Management.

Kwok-Kee Wei (isweikk@cityu.edu.hk) is the Dean of College of Business at City University of Hong Kong. He is the Chair Professor of Information Systems in the College of Business at City University of Hong Kong, and he is the Fellow of the Association of Information Systems. His articles have appeared in Management Sciences, MIS Quarterly, Information Systems Research, Journal of Management Information Systems, and so on. His current research area includes knowledge management systems, human-computer interaction, innovation adoption and management, and electronic commerce. 


\title{
Helpfulness of Online Product Reviews as Seen by Consumers: Source and Content Features
}

\begin{abstract}
\end{abstract}
Online product reviews are important determinants of consumers' purchase decision. Although prior research have articulated the benefits of online product reviews, there are few investigations on whether or not they are perceived as helpful by the consumers. Product review helpfulness is conceptualized as a second-order formative construct, which is manifested by perceived source credibility, perceived content diagnosticity, and perceived vicarious expression of the product review. In this study, we conducted a laboratory experiment to investigate product review helpfulness as well as its corresponding antecedents from the product review feature perspective (i.e., source- and content-based review features). Findings from the study are threefold. First, the results of the data analysis support the theoretical conceptualization of product review helpfulness as a formative construct. Second, the results support the notion that the source- and content-based review features have direct impact on product review helpfulness. Consumers perceive customer-written product reviews as more helpful than those written by experts; they also perceive a concrete review as more helpful than an abstract review. Third, we find an interaction effect of the source- and content-based features of product review on review helpfulness. A customer-written product review with a low level of content abstractness yields the highest perceived review helpfulness.

Keywords: product review, source-based feature, content-based review feature 


\section{INTRODUCTION}

Product reviews facilitate consumers' purchase decision in an online shopping environment. A 2010 research report by eMarketer reveals that 92 percent of online consumers read product reviews before they make a purchase decision [28]. This observation is also echoed by scholars who suggest that consumers are often inclined to acquire product review information to enhance the formation of informed purchase decisions [24, 26, 43]. There are numerous easily accessible product reviews posted in various online shopping websites that compete for consumers' attention; hence, the key priority of a website manager is to select and publish more helpful reviews to minimize consumers' inclination to abandon visits to their websites and strengthen their effectiveness in attracting new customers [19]. Although presenting helpful reviews to consumers has become one of the most useful marketing tools of a company (e.g., Amazon.com), the question of what type of product reviews on online shopping websites can be evaluated as helpful by consumers, has not been thoroughly researched [53].

Before answering this question, understanding what review helpfulness refers to is essential. Our review of the prior studies reveals that inconsistent conceptualizations generated from previous research cannot present a clear and definite picture of what review helpfulness refers to. Some scholars investigated the correlation between review helpfulness and review usefulness. For instance, Pan and Zhang (2011) define review helpfulness as how consumers perceive product reviews as useful in performing their shopping tasks [53]. Understanding the central idea of "review helpfulness" [48] and the "big" concept of "usefulness" is difficult. Other researchers examine review helpfulness and its connection to review diagnosticity. For instance, Mudambi and Schuff (2010) define review helpfulness as a peer-generated evaluation that facilitates the process of consumers' purchase decision [51]. They argue that review helpfulness can be seen as 
a reflection of review diagnosticity. Originally, diagnosticity refers to "the extent to which a given piece of information discriminates between alternative hypotheses, interpretations, or categorizations” [34]. In this regard, review diagnosticity can only represent the level of ambiguity in the product review information [35].

Hence, we re-conceptualize review helpfulness in this study. Following a study on helping behavior, which argues that helpfulness has three dimensions, namely, trustworthy perception, problem-solving, and insight mediation [2], we conceptualize review helpfulness as having three dimensions, namely, perceived source credibility, perceived content diagnosticity, and perceived vicarious expression. From our review of the extant literature, which explores the characteristics of helpful review, we find that these three dimensions compose the concept of helpful review (see Table A1 in Appendix A). Based on this conceptualization, we then argue that the consumers' perception of a piece of review as helpful depends on the consumers' subjective attitude toward both review source and review content. Although a considerable amount of prior studies have considered review helpfulness as an objective voting ratio by consumers (e.g., was this review helpful to you? Yes/No) [29], such voting mechanism (i.e., the higher the votes the more helpful the review is perceived to be) has its own intrinsic disadvantages [71]. For instance, the winner circle bias would occur (i.e., reviews with more accumulated votes get more attention than the less voted ones) apart from the early bird bias (the first reviews to be published tend to get more votes). Therefore, we revert to the investigation of how a consumer would perceive reviews with different sources and contents for two reasons: (1) objective voting mechanism cannot really screen out helpful reviews, and (2) to answer the question as to what type of product reviews in online shopping websites can be assessed as helpful. 
The two main types of reviews in online platforms are expert-written reviews and customer-written reviews. Expert-written reviews refer to those written by expert reviewers often hired by popular e-commerce vendors or portals [1], whereas customer-written reviews typically refer to those posted by prior buyers who have used or experienced a focal product [62]. Psychologists and behavior researchers argue that the source of information significantly influences the consumers' attitude toward the information. Experts and customers typically play different roles in the transmission of different signals to consumers [11, 59]. Other than the important role of review source, review content can also influence consumers because they typically learn about products from what the reviewers said [76]. In this study, we focus on examining the impact of review abstractness on consumers, because reviews in different levels of abstractness send different signals to consumers and transmit distinct vicarious expressions to them [63]. We conducted a controlled experiment to test the respective effects of the source or content on the perceived review helpfulness (including their interaction effect). This research enriches our current understanding of the concept of product review helpfulness and what types of reviews are perceived as helpful.

\section{LITERATURE REVIEW}

\section{Product review helpfulness}

Research on helping behavior provides a pertinent foundation in investigating product review helpfulness in the context of online shopping. With limited time and resources, consumers look for relevant information from a large volume of information to alleviate purchase uncertainty. Product reviews - be they from customers or experts - provide potential buyers relevant information on the usage experience and product features of the target product; such knowledge 
facilitates the purchase decision process [51]. From the perspective of helping behavior, the provision of product reviews is regarded as a helping deeds from others [8]. When consumers read product reviews from the Internet, they perceive the product review as an endorsement of the reviewers' desire to help, commitment, and reciprocity for facilitating other consumers' purchase decision [72].

In the present paper, we define "product review helpfulness" as the extent to which consumers perceive the product review as being capable of facilitating judgment or purchase decisions. Product review helpfulness is a formative construct consisting of three dimensions: (1) perceived source credibility, (2) perceived content diagnosticity, and (3) perceived vicarious expression. The theoretical foundation of this definition comes from Bach's (1967) research on helping behavior. In the research area of helping behavior, helpfulness has three dimensions: (1) trustworthy perception, (2) problem-solving, and (3) insight mediation [2]. In relation with helping behavior and online shopping process, consumers (advisees) look for product reviews written by customers or experts (advisors) and get help from them to facilitate their own purchase decisions [45]. In this sense, the three constructs (i.e., perceived source credibility, perceived content diagnosticity, and perceived vicarious expression) are consistent with the dimensions of helpfulness found in the helping behavior research area.

The perceived source credibility (trustworthy perception): Trustworthy perception refers to the advisees' perception of the trustworthiness of the advisors as to whether they provide helpful behavior or information faithfully, rather than evasively pretend to be "warm-hearted" [2]. In the context of product review, this notion is consistent with perceived source credibility. Perceived source credibility refers to the credibility of the authors' correct review information as perceived by the consumers [37]. When advisees regard the advisors as credible (trustworthy), even if the 
advisees and advisors are hostile to each other, they will still be open-minded and "fight it out" constructively; such open-mindedness will greatly help them solve the dispute [2]. When advisors (source credibility) are perceived as trustworthy, the advisees and advisors can exchange "honest feelings of critique and annoyance tend to open rather than close the gates for deeper sharing of warm, positive feelings” [2].

The perceived content diagnosticity (problem-solving): Problem-solving refers to the provision of advice and intention of solving current reality problems [2]. In the context of research on helping behavior, problem-solving occurs when the advisors give advisees information about what to do, reinforcing the most helpful experience of getting pointers on problem resolution [2]. The information conveyed from advisors to advisees is regarded as the most important determinant of the performance of problem-solving [34]. If the information from advisors is unreliable, it cannot help the advisees discriminate interpretations and potential solutions to the problem. As a result, the advisees cannot perceive the problem as "solved," even if the advisors talk to them lengthily. The notion of perceived content diagnosticity is consistent with the concept of problem-solving when the advisees confront the problem of making shopping decisions in the context of online purchasing. Perceived content diagnosticity refers to the extent to which a given piece of review information discriminates between alternative interpretations and solutions of a problem [34]. In this sense, acquiring highly perceived diagnostic information allows advisees to solve their problem more effectively. In the context of product review, when the review content has a high level of diagnosticity, it can help the consumers differentiate between benefits and concerns of the focal product. Compared with the low level of diagnostic information, the high level of diagnostic information can help solve the problem of whether or not the consumer should buy the focal product. 
The perceived vicarious expression (insight mediation): Insight mediation refers to “insights into other people’s functioning, understanding their inside world better and sensing better what makes them tick" [2]. When the advisees perceive something as being helpful, they have the feeling that they are gaining insights into the advisors' inner world, allowing them to see why and how the advisors offer help. Consistent with insight mediation, perceived vicarious expression refers to the degree to which reviews convey vivid experiences of a product that could be felt by readers. The concept of vicarious expression originated from the notion of vicarious experience in social learning theory [31]. If reviews have high levels of perceived vicarious expressions, the consumers can gain insights into why an author wrote the reviews in such style, thus helping them understand the author's point of view as they evaluate the target product. In the same vein, by reading product reviews with high level of vicarious expression, consumers can learn the usage experience as a result of consuming the target product through the review [2]. As a result, the product reviews can mediate the insights of the authors and help the consumers facilitate the decision process based on the authors' expression of their vivid experiences.

\section{Product review features}

Prior studies on product review have focused on some key features of online product review, such as valence of review [17, 21], volume of review [44], source [5], and review content [47]. Among them, two features of product reviews, the source-based (e.g., authorship of product reviews) and content-based (e.g., content abstractness) features, are important for review helpfulness [4]. Extant literature on assessing product review helpfulness revolves around these two features (see Table A1 in Appendix A for detailed reviews of the papers). Among the source- and content-based product review features, the authorship and the abstractness of the 
content are the two important indicators of product review helpfulness. These complement the question (i.e., “Who says what?”) that, in turn, supports the decision behavior. Scholars have argued that source and content are two important perspectives when assessing the impact of information [27]. For instance, De Bono and Harnish investigate the impact of authorship (e.g., expert or attractive male message deliver) and the quality of content argument on the persuasiveness of counter attitudinal message [23]. In addition, Borgida and Nisbett argue that the abstractness of information is a critical factor for decision behavior [6]. Recently, scholars have found that consumers are greatly concerned about the authorship and the abstractness of product reviews when they evaluate the helpfulness of the reviews [19, 29]. As a result, we believe that the authorship and the abstractness of product reviews are worthy of examination.

Prior research on product review features and review helpfulness are classified into two categories. The first category focuses on the assessment of product review helpfulness from the perspective of the source-based feature [22, 23, 25, 29] by considering the review message believability of the product reviews [46]. Its primary concern is evaluating product review helpfulness in terms of the persuasiveness of the information they contain. These authors argue that the authorship of product reviews has a non-trivial impact on the persuasiveness of the product reviews, thus affecting its helpfulness [46]. In addition, De Bono and his colleagues find that different sources of information (from experts or non-experts) could have varying impacts on the persuasiveness of the information [23]. Extending this finding, scholars in this category shifted their attention to determine how the authorship of product reviews influences the helpfulness of the reviews [23, 25, 29]. Specifically, Forman and colleagues observed that the product reviews' source identity-descriptive information (e.g., authorship of the product reviews) can be used to supplement or replace the product information when consumers evaluate the 
helpfulness of the online reviews [29]. Other scholars, in a similar vein, discover a high correlation between the disclosure of the authorship of the product reviews and the consumers' evaluation of the reviews' helpfulness [23].

Meanwhile, the second category of studies centers on the assessment of product review helpfulness from the perspective of the content-based feature [40, 51, 62, 65] with explicit consideration of content abstractness. Scholars adopt the concept of diagnosticity to reflect how online buyers perceive product reviews as helpful in the evaluation of product quality [55, 56]. They argue that the established connection between product review content diagnosticity and perceived helpfulness is highly relevant to the context of online reviews [51]. Probing further, researchers focus on how the content-based characteristics of product reviews (e.g., valence and abstractness of product reviews) influence content diagnosticity and helpfulness [34, 51, 65]. For instance, one study finds that consumers perceive product reviews as diagnostic, only when the reviews transmit clear information [34]. Another study discovers that the volume of review content could significantly influence the perceived diagnosticity of product reviews [62].

\section{RESEARCH MODEL AND HYPOTHESES}

After understanding the concept of product review helpfulness, we develop a research model that uses product review helpfulness as a formative construct manifested by perceived source credibility, perceived content diagnosticity, and perceived vicarious expression. To determine product review helpfulness, we posit that consumers evaluate review helpfulness by determining both the authorship and the content of product reviews. In this study, we focus on the different authorships of reviews, that is, the expert-written product reviews and the customer-written product reviews. With regards the various review content provisions, we classify them as 
concrete and abstract. A concrete review refers to one that contains certain information transmitted by the reviewer. In this type of review, the reader has little room to generate other interpretations [64]. By contrast, an abstract review refers to one that could transmit uncertain information to a reader with more than one interpretation (e.g., "I am so proud of it," "I am sure this is the best product I have bought”). The current study examines both the main and interaction effects. Figure 1 shows the research model of the present paper.

-------Insert Figure 1 about here-------

\section{Main effect}

We propose that the authorship and content abstractness of product reviews have individual impacts on product review helpfulness. The authorship of the product reviews is important in influencing consumers' perception as to their helpfulness [29]. Product reviews in the mundane shopping websites largely originate from former or current customers and experts [69]. The expert-written product reviews are generally written by expert reviewers often hired by popular e-commerce vendors or portals. A prior study [1] observes that expert-written product reviews are often in-depth and unbiased in their product evaluation. Furthermore, these reviews are typically product-oriented and contain extensive product information. In comparison, customerwritten product reviews are evaluations or current customers based on their personal experiences and viewpoints. Park and his colleagues (2007) argue that customer-written product reviews provide users with experience-oriented product information. Hence, consumers perceive these reviews as representations of the real product usage experience, making them more understandable and believable than the expert-written product reviews [54]. Consequently, consumers perceive customer-written product reviews as helpful when selecting a product or service [60]. Thus we posit the hypothesis below. 
Hypothesis 1: Compared with an expert-written product review, the customer-written product review is perceived to have higher review helpfulness.

Reviewers can freely choose either concrete or abstract way of stating their experiences on a focal product, enabling a reader to generate different interpretations. On one hand, the reviewers can express their comments on a specific characteristic of a product regarding how they experience it. For instance, one reviewer states, "[I was] so surprised at the speed of this CPU, I have to say i5 is indeed much faster than the i3 processor, [which shows] when I am playing the game, so on." From such type of expressions, a reader can easily grasp the information the reviewer transmits, with no confusing interpretations. On the other hand, the reviewers may also evaluate the product abstractly. For instance, when a reviewer states, "It is really a good notebook, and I am so proud of it," the reader cannot ascertain the actual performance of this product and what accounts for the good quality of the notebook although he can understand this as a positive message. Thus, the reader finds it easy to generate other interpretations on the performance of the product. To this end, we argue that a concrete review is perceived as more helpful than an abstract review because consumers can better judge the focal product through the former. Thus, we posit the hypothesis below.

Hypothesis 2: Compared with an abstract product review, a concrete product review is perceived to have higher review helpfulness.

\section{Interaction effect}

The authorship and the content abstractness of product reviews have an interaction effect on product review helpfulness [36]. In the light of the preceding studies, we argue that the sourceand content-based features of the product reviews are essential in assessing their helpfulness. 
Indeed, product review helpfulness is considered as the extent to which consumers perceive their capability to facilitate judgment or purchase decisions [53]. Conventional wisdom dictates that consumers evaluate the product review features (source- and content-based) in a holistic manner [46]. If the product review lacks authorship, given that the review content has various levels of content abstractness, the consumers cannot identify "who" evaluates the content [29], and fail to perceive it as helpful [14]. Likewise, if the review message shows the authorship explicitly, but fails to provide a pertinent content, the consumers will typically not consider the review as helpful [73]. Leading from this, we conceive that the effect of the review abstractness on the evaluation of the review helpfulness should be contingent on who posts the reviews. In particular, potential consumers would perceive the reviews being from customers as more helpful when the concrete reviews provided by either an expert or customers. It is because the customer-written concrete product reviews, which focus on talking about the specific characteristics of a typical product from peer customers’ perspective, would more easier for a consumer to grasp others’ using experience as regard to the product, and generate the similar experience with himself/herself [63]. In this regard, the generated similar usage experience of other customers could facilitate the present consumer to evaluate the potential benefit/cost of the shopping decision behavior, compared with expert-written product review [68]. Thus, consumers would perceive the concrete customer-written product review more helpful. Hence, we posit:

Hypothesis 3: In the case of concrete product review content, a review written by a customer is perceived to have higher review helpfulness than one written by an expert.

Considering the abstract product reviews written by the expert and the prior customer, the content nature of the abstract product review could inhibit the well-rounded understanding of the product feature information and prior usage experience [38]. In this regard, we conceive that the 
abstract customer-written product review may generate lower review helpfulness than the abstract expert-written product review. As discussed earlier, the customer-written product review could provide present consumers with experience-oriented product information, which could result in a representation of peer consumers' evaluation and real usage experience assessment of the target product [54]. However, in the abstract product review context, the abstract content may not contain sufficient expression of experience-oriented product information from customerwritten product review; likewise for the case of abstract expert-written product review. As a result, present consumers could not grasp the detailed product specifications and the usage evaluation of focal product from product review, but rather the general overview of the target product. For instance, the abstract customer-written review summarizes: "I found this laptop is good for work in office. It is well designed and it has powerful CPU and large memory chips....”; the abstract expert-written review summarizes: "This model of laptop has gorgeous design and hardware features. It is very nice for the work in office as well as....”. When the reader is unable to fully understand the product through the reviews, it is likely that he/she may assess the customer review to be poorer since he/she may speculate that the peer may not unwilling to fully disclose the consumption experience [2, 65]. In this regard, compared with abstract expertwritten review, the abstract customer-written review could not meet the consumers' envision of customer-written review as the vivid, easier to use, and trustworthy product review [34]. Hence, the parity between the envision and the actual performance of customer-written review could signify the uncertainty of the product information [53], which could result in the perception of less helpful of product review. Therefore, we conjecture that under such situation when abstract review is provided, the review written by customer may perceive to be less helpful than expertwritten review. 
Hypothesis 4: In the case of abstract product review content, a review written by customer is perceived to be of lower review helpfulness compared to one written by an expert.

\section{METHODOLOGY}

\section{The experiment design}

We designed a $2 \times 2$ factorial experiment to examine the hypotheses. Two authorship situations (expert-written and customer-written) combined with two content abstractness situations (abstract and concrete) generated four treatment groups. The design details of the treatment groups are shown in Table 1.

-------Insert Table 1 about here--------

For each of the treatment groups, we presented a mockup online shopping website to the subjects. The website consists of two modules: (1) the product information presentation module, which shows the product feature information to the subjects, and (2) the product review presentation module, which details the corresponding product review information and indicates that the review has been written by either experts or customers on voluntary basis. The setting of the mockup website is similar with the style in mundane online shopping website. We studied the commercial implementations and extracted the product content of commercial websites to manipulate the provision of product reviews [43]. When subjects logged in the experiment website, they firstly saw the scenario for the experiment. After reading the scenario, the subjects proceeded to the shopping process, in which the two modules presented the product information and product review to the subjects. When the subjects finished reading all of the aforementioned information, they decided whether or not to buy the product. After making the decision, the subjects were asked to finish answering the follow-up questionnaire. 
The scenario for the experiment was designed as purchasing product to the closest friend. Such a purpose of purchasing for one's closest friend is common in the consumer behavior literature [66]. This scenario is also consistent with most studies on information-seeking and decision-making behavior, although inducing mundane realism is also necessary [74]. In the mockup website, we also used a fictional brand to rule out the brand effect [70]. The volume of the product features information was controlled within a manageable level [61]. In addition, we controlled the volume, length, and valence of the product review to make them similar among the four treatment groups [54]. The two differences among the treatment groups were the provision of different authorship and content abstractness. To minimize distraction from imagebased cues from the product reviews, the customer-written and expert-written reviews were entirely text-based.

We measured the dimensions of product review helpfulness by using subjective measurements. Table 2 summarizes the operationalization of the dimensions of product review helpfulness. The detailed measurements are found in Appendix B.

-------Insert Table 2 about here-------

In the present paper, we conceptualize product review helpfulness as a "reflectiveformative” second-order construct [67], which means that the three dimensions (i.e., perceived source credibility, perceived content diagnosticity, and perceived vicarious expression) formatively constitute the review helpfulness. Each of the dimensions is reflectively measured. For the items that reflectively measure the three dimensions, we adopted the items from prior literature and made sufficient adjustments to contextualize them. To ensure the quality of the adjustments, we followed the standard guideline of card sorting in evaluating all of the items [20]. We invited 12 IS scholars to participate in the expedition. The first round of card sorting 
was the open card sorting. 6 IS scholars evaluated all the items and classified them into different categories and named them. After the first round card sorting, we provided the closed card sorting to the rest of 6 IS scholars. The results of the card sorting showed that all of the items were classified into the current categories and the names of categories were appropriate to the research design. These results indicated that the finalized items are suitable for the measurement.

\section{The laboratory experiment}

A total of 120 subjects were recruited from working professionals and were randomly assigned to 4 treatment groups, with 30 subjects in each treatment group. Among them, 54 (45\%) were females and 66 (55\%) were males, with an average age of 23 years. This demographic data of subjects generally match with the main cohort of China Internet users who are typically in the 20s [18]. We recruited the subjects by advertising in a popular Bulletin Board System (BBS) most frequently visited by working professionals in a major city in China. In the posting, we detailed the purpose of the study that is to understand individual behavior towards product reviews. A hyperlink to our registration system was included in the posting. It is difficult to track the precise number of people who saw our experiment advertising, as we do not have access to the BBS system log. However, we learnt from the BBS system administrator that on average around 340,000 unique IP addresses were recorded per day. Based on this estimation, we deduced that around a thousand visitors saw our advertisement per day (in total there are around 30 different forum postings across 10 forum topics).

For the registration system, we set the maximum number of people allowed to register for the experiment to be 144 (36 people * 4 treatments). In the registration, the people were not known of the exact treatment that they were subjected to but they could indicate their preferred timing of participation. It was only during the experiment that our experimental system randomly 
determined the treatment each of the participating subject involved. In our experiment, we only required 120 subjects but we had 144 people signed up (around 20\% more). This is because we expected some of the people might not eventually turn up for the experiment. The recruitment was completed within two days.

One day before the experiment, we used several means, including phone calls and instant messaging, to remind the registered subjects about the experiment. Overall, 127 people turned up for the experiment. Among them, 7 were compensated with a small token of appreciation without participating in the experiment. As intended, 120 subjects participated in the experiment. To ensure experimental realism, the subjects were individually given monetary incentives of USD5.00.

The experiment was conducted in the following sequence. When the subjects came to the laboratory, they were assigned to one terminal. Then, they logged in to the simulated website using a designated account. Next, the subjects were asked to fill in their demographic information, after which they listened to pre-recorded instructions and viewed the introduction of the experiment system. This illustrated the features of the experiment system to the subjects and provided them with instructions on how to view the product review and how to shop in the experiment system. The two product used in the experiment system were mobile phone and laptop. The subjects were asked to purchase one product from each of the product categories. The order of the purchasing sequence was also randomized. After reading the product feature information and the product review, the subjects decided whether or not to buy the product. Then they filled out a questionnaire. When the subjects finished the experiment, they were given the monetary incentive and dismissed. This setup is consistent with most experimental studies on 
information-seeking and decision-making behavior [33]. Figure 2 shows the screenshots of experiment system.

-------Insert Figure 2 about here-------

\section{DATA ANALYSIS}

In order to avoid sampling bias, the subjects' demographic statistics, such as age and gender, were randomized to minimize the contingent effect. Further checks indicated no sign of any significant difference for subjects among the 4 treatment groups regarding age $(\mathrm{F}=2.80, \mathrm{p}>.10)$. In addition, no significant differences across the treatment groups in terms of gender ratio were observed in relation to the Kruskal-Wallis test ( $\left.\chi^{2}=1.47, \mathrm{p}>.10\right)$. Moreover, no significant difference of the product review helpfulness was observed between the two types of product $\left(\right.$ mean $_{\text {laptop }}=4.31$, mean $\left._{\text {mobilephone }}=4.49 ; \mathrm{t}=-1.49, \mathrm{p}>.10\right)$.

\section{Manipulation check}

The manipulation check was conducted to ensure that our manipulation of the authorship and the content abstractness of the product reviews was successful [54]. The subjects were asked to indicate the authorship of product reviews they had read (i.e., customer-written product review or expert-written product review). The authorship indicated by all the subjects tallied with those expressed in the reviews. For the content abstractness, we did not directly ask the subjects because we did not want them to guess that there could be other types of product reviews, which were not presented to them. Such suspicion could have impact on their behavioral responses to the manipulations. Hence, to address this, we did the following measures. First, two co-authors visited a popular shopping website to extract a list of product reviews for mobile phone and laptop. The product reviews were then studied and sorted by the two co-authors based on the 
level of content abstractness. Reviews that were not distinctively concrete or abstract were removed. Examples of concrete reviews include "This laptop has Core i5 processor, it has over 1.5 times on the performance better than the old model; The memory is 8G, it can run most of the PC games, such as 'StarCraft 2', 'Call of Duty: Modern Warfare’”. Examples of abstract reviews include "it is the best laptop I've bought; it is great! Buy it”. Next we invited 3 IS scholars to evaluate the two types of product review content (abstract vs. concrete). They indicated that there was a significant difference in term of content abstractness between the abstract reviews and concrete reviews.

\section{Measurement model}

All the dimensions were reflectively measured for the first-order constructs, and then the item reliability was examined. The results indicate that all the items for measuring the three dimensions can reliably represent the corresponding constructs. Specifically, the Cronbach's alpha values were .87 ( 3 items), .89 (3 items) and .89 ( 3 items) for perceived source credibility, perceived content diagnosticity and perceived vicarious expression, respectively. Next, the convergent validity and discriminant validity were examined. For the convergent validity evaluation, the main criterion is that the average variance extracted (AVE) values of the constructs should be greater than the .50 cut-off. Table 3 summarizes the measurement model results; as can be seen, all the Cronbach's alpha values and AVE values meet the threshold requirement.

For the discriminant validity evaluation, we compared the square roots of AVE values with the correlations among the latent variables. The criterion for this evaluation is that the square roots of AVE values should be greater than the corresponding correlations of each latent variable. In addition, the factor loadings of the items should produce higher load on the corresponding 
construct than on the other constructs. Table 4 shows the factor loading results. All the evaluations of the convergent and discriminant validity indicate appropriate results for the measurement model.

--------Insert Table 3 about here--------

\section{Formative measure of dependent variable}

Interpreting the formative construct is very important in the information systems (IS) discipline [58]. In the first step of the data analysis, we evaluated product review helpfulness and examined whether or not the results of the data analysis support the proposition of the formative construct [58]. In the present paper, we conceptualized product review helpfulness as a "reflectiveformative" second-order construct. We followed the guidelines in interpreting the results of formative measurement [10]. In addition, as suggested by prior literature, we used the PLS algorithm to test the formative construct [57].

As suggested by Cenfetelli and Bassellier, the interpreting formative measurement consists of several steps [10]. Figure 3 presents the weights of the three dimensions. The results show that all of the dimensions are significantly weighted $(\mathrm{p}<.01)$. In addition, no multicolinearity problem exists among the three dimensions, with the VIF values being smaller than 3.33. Specifically, the VIF values for perceived source credibility, perceived content diagnosticity, and perceived vicarious expression are 1.56, 1.23 and 1.28, respectively. Moreover, no co-occurrence of problems with negative and positive weights is observed, as with absolute and relative contribution problems. For the nomological network effect, we used redundancy analysis in terms of the PLS algorithm. We used some other items from prior literature to reflectively measure product review helpfulness [53]. For example, "I perceive the product review [as] 
helpful for my purchase decision" or "I perceive the product review [as] useful for making a purchase decision." The path coefficient from the formative product review helpfulness and the reflective product review helpfulness is .92 (see Figure 4), which indicates a good degree of formative indicator validity [10]. As a result, the data analysis supports the proposition of the "reflective-formative” second-order construct of product review helpfulness. Table 5 presents the details of the analysis.

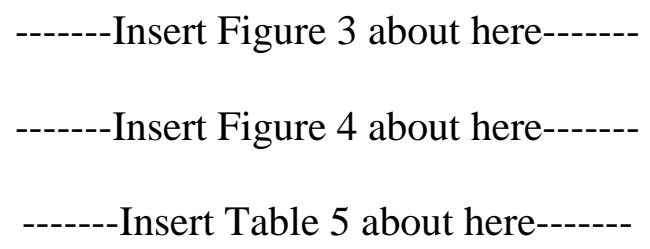

\section{Hypotheses testing}

Hypothesis testing was conducted at a five-percent level of significance. Table 6 shows the descriptive data of the dependent variables. Here, we used the factor score of review helpfulness for the hypotheses testing, because of the formative construct conceptualization of review helpfulness. Prior studies indicate that the online shopping experience, prior product knowledge, and duration of the experiment may influence the perception of product review helpfulness [26]. A univariate test using the ANCOVA was conducted to control for the possible influence of these variables on product review helpfulness. Significant effects of the authorship, content abstractness, and their interaction effects are also observed for the dependent variable (Table 7).

-------Insert Table 6 about here-------
--------Insert Table 7 about here--------

In addition, we deployed the independent samples T-test to examine Hypotheses 1 and 2. Hypothesis 1 posits that the consumers perceive a customer-written product review as having higher review helpfulness than the expert-written product review. The results of the hypothesis 
testing are indicative of a significant difference in the product review helpfulness between the customer-written and the expert-written product reviews $(\mathrm{t}=-2.70, \mathrm{p}<.01)$. Subjects perceived that the customer-written product review has higher review helpfulness than the expert-written product review ( $4.55_{\text {customer review }}>4.25_{\text {expert review }}$ ). Hence, Hypothesis 1 is supported. Meanwhile, Hypothesis 2 posits that the consumers perceive a concrete product review as having higher review helpfulness than the abstract product review. The results show a significant difference in the product review helpfulness between these two conditions ( $t=5.50, \mathrm{p}<.01)$. Hence, Hypothesis 2 is supported ( $\left.4.70_{\text {concrete }}>4.10_{\text {abstract }}\right)$.

For the interaction effect of the authorship and content abstractness, we conducted the simple effect analysis by first splitting the data based on the content abstractness and then conducted the independent sample T-test to compare the means between the treatment groups. The results reveal that the concrete review posted by customers (mean=4.94) is significantly perceived to have a higher helpfulness than the review posted by the experts (mean=4.44; $\mathrm{t}=3.26$, $\mathrm{p}<.01)$. Thus, Hypothesis 3 is supported. In addition, when the provided review is abstract, the result indicates that there is no significant difference $(\mathrm{p}>0.1)$ posted by experts (mean=4.06) and customers (mean=4.15). Therefore, Hypothesis 4 is not supported. The detailed statistics are presented in Table 8. Figure 5 shows the interaction effect.

-------Insert Table 8 about here--------

-------Insert Figure 5 about here-------

\section{DISCUSSION}

This study enhances our understanding of the meaning of product review helpfulness and what types of reviews are perceived as helpful in terms of both the review source and content features. Thus, based on literature on helping behavior, we re-conceptualized review helpfulness as a 
formative construct consisting of perceived source credibility, perceived content diagnosticity, and perceived vicarious expression. Both the theoretical argument and the empirical assessment support our conceptualization of product review helpfulness in relation to the reviews' sourceand content-based features, which independently influence consumer perceptions of review helpfulness. The customer-written review is considered as more helpful than that posted by experts. In addition, the concrete expression by either the customer or expert is more helpful to a consumer who is making a judgment. Specifically, review information expressed with less additional explanations is perceived as more helpful.

In line with the main effect, significant interaction effects also show that the concrete customer-written product review is perceived as more helpful than the concrete expert-written review. In addition, with the change of review content abstractness from concrete to abstract, although the abstract expert-written review yields the lowest product review helpfulness, it has no significant difference from the abstract customer-written review. Thus, consumer perception of the product review helpfulness is greatly determined by the review content itself. However, given the concrete review provision circumstance, the reviews posted by customers or experts have different helpfulness values. This result implies that the insignificance only occurs under the abstract review provision condition. Thus, given the provision of abstract review, the review content determines consumer perception on the evaluation of review helpfulness, regardless of the source of review. Indeed, a considerable amount of previous studies investigated the process by which information content and information source influence consumer attitude and judgment (e.g., $[15,50])$. In line with the findings of prior research, we conclude that given the abstract review provision, the consumers tend to process the review information in a systematic way; in 
turn, this greatly influences the impact of the review source on consumer perception of the review helpfulness evaluations [12].

Other than the hypotheses currently listed, we performed further analysis in this study. The result reveals that although the concrete expert-written reviews seem more helpful than the abstract customer-written reviews, no significant difference is found between them $\left(4.44_{\text {concrete- }}\right.$

expert $>4.15_{\text {abstract-customer, }} \mathrm{p}^{>} .10$ ). We conceive that the possible underlying reason is that consumers have difficulty comparing these reviews due to the individual effects of the source-and contentbased product review features. As revealed by the analysis results, the concrete reviews are typically more helpful than abstract ones, while the consumer reviews are more helpful than those written by expert. The tradeoff of the impact of the two distinctive determinants on the product review helpfulness is still unclear. We suggest that further studies be conducted on this topic. A pertinent research question should be "Among the source-and content-based product review features, which influence the product review helpfulness most?”

\section{Theoretical contribution}

In recent years, interest in studying online reviews has increased. IS and marketing researchers agree that employing the best strategy to screen and present helpful reviews plays an important role in influencing consumer product judgment and purchase decision making (e.g., [30, 53]). Our research contributes to the literature in three important areas.

First, considering the inconsistent and controversial conceptualizations of the review helpfulness in prior studies, this study re-conceptualizes the concept of review helpfulness. Specifically, some previous studies examine the review helpfulness problems with no clear definition of helpfulness (e.g., [7]), while others present different conceptualizations. For instance, Mudambi and Schuff (2010) connect the review helpfulness to the review diagnosticity 
[51], while Pan and Zhang [53] argue that the helpfulness can be used interchangeably with review usefulness. These different definitions and concepts prevent the readers from comprehending the actual meaning of review helpfulness; thus, how a consumer perceives a review as helpful is not clearly understood. Based on the research on helpful behavior, we theorize that review helpfulness is a formative construct consisting of the perceived source credibility, perceived content diagnosticity, and perceived vicarious expression. This new conceptualization confirms most of the components identified in prior research (Table A1 in Appendix A) as well as provides a comprehensive and foundational concept for future research.

Second, although the review helpfulness has become the focus of prior studies, and a considerable amount of research has attempted to explore the components of helpful reviews (e.g., [9]), most of these studies typically consider the most popular reviews as helpful ones [75], and scant attention has been paid to investigating the types of reviews that are actually helpful for a consumer. In line with previous studies examining the informational influence on a consumer from the perspective of either information source or content, the experimental results suggest that either the review source or content individually influence consumer evaluations as well as interactively determine consumer perception of product review helpfulness. To the best of our knowledge, our study is the first attempt to investigate the interaction effect between the source- and content-based review features. The findings significantly advance the current understanding of what types of reviews are really helpful for a consumer to arrive at an informed judgment on whether or not he should buy a focal product.

Third, this study provides in-depth comparisons of review helpfulness with different pairs of review content and review sources. Past studies have focused on how the review content influences how a consumer perceives a product review’s helpfulness (e.g., [62]), but they 
typically ignore the contingent effect caused by the review source. Previous studies have also emphasized the critical role of the review source in influencing consumer judgment (e.g., [29]), but failed to examine the underlying interactive effect of the review content itself. The current study reveals that the concrete review is not always superior to the abstract reviews, and similarly, the customer-written product review is not always perceived as more helpful than the expert-written product review. Thus, our findings encourage researchers to consider the intrinsic complex interaction effect between the review source and review content when investigating the impact of reviews on consumers in future research.

\section{Practical implications}

This study also offers two key implications to practitioners.

First, in online shopping websites, website managers are eager to leverage product reviews to retain consumers. Although these managers provide a platform where consumers or experts to post their reviews, they have not provided the needed help to assess product review helpfulness or to incorporate the helpful product reviews to enhance website popularity. Consumer psychologists have observed that a helpful product review significantly affects consumer perception and decision-making behavior in the online shopping context [13, 42]. Hence, the online shopping website manager must identify a helpful product review and increase its quality and quantity. To this end, we provide insights for online shopping website managers to assist them in establishing clear goals while providing them with website design guidelines. Online shopping websites can consider incorporating an IT artifact that provides automatic suggestions for improving the content diagnosticity and the perceived vicarious experience of the product reviews. 
Second, we provide the guidelines for the online shopping website manager to identify a helpful product review. Our results suggest that a highly helpful product review should have good source credibility, high content diagnosticity, and good vicarious experience. Based on the results of this research, the website manager can evaluate the helpfulness as a priori, and utilize the product review more strategically. Specifically, the new version posting system can place product reviews according to review helpfulness (i.e., posting the most helpful product reviews in prominent positions).

\section{Limitations and research directions}

This study has several limitations that serve as suggestions for future research.

First, although we theorize our new conceptualization based on extant research on helpful behavior, this conceptualization may potentially limit our understanding using other theoretical perspectives. Although we have successfully presented most of the components of helpful reviews that prior studies referred, we cannot ensure that no other sets of important characteristics exist for formulating the review helpfulness in terms of other theoretical foundations. Therefore, we strongly suggest that future studies explore the possible meaningful dimensions of review helpfulness using other theoretical perspectives.

Second, in the experiment, we considered only the search products (e.g., electronic goods) and corresponding product reviews. We chose to study electronic products because numerous online shopping websites sell such products (e.g. Amazon.com). A rich data source exists for acquiring product information and related product reviews. We developed a research design that is consistent with most studies in terms of online shopping and decision-making behavior [33]. Moreover, we conducted several pretests to assess consumers' willingness to purchase using 20 product categories. This was done to ensure that the subjects were interested in the selected 
electronic product categories. The selected product categories in the experiment were ranked as the two highest items in the pretest. Thus, it can be said that the subjects were intrinsically interested in making purchase decisions on these products and acquiring knowledge from product reviews. However, other product categories (e.g. clothing and cosmetics, belonging to the experience products) must be investigated in future research to generalize our findings.

Third, in the mockup website, we indicated that the review content was contributed on a voluntarily basis by experts or consumers depending on the manipulation. Therefore, future research could examine the influence of review contributions by authors who are paid versus those who contribute voluntarily.

\section{CONCLUSION}

Electronic commerce has grown and continues to grow exponentially. Following the worldwide financial recession, electronic commerce has become a new economic growth point. Hence, it is essential to gain a better understanding of how online product reviews are best utilized during the decision-making process. The helpfulness of a product review, as one of the most important indicators, reflects the extent to which consumers perceive the review in facilitating judgment or purchase decisions. A helpful product review significantly influences consumer purchase decisions. The present study is a modest step toward developing a theoretically sound measurement for product review helpfulness in the online shopping context. The implications will be beneficial to both scholars and practitioners.

\section{ACKNOWLEDGEMENT}

The work described in this paper was fully supported by the Strategic Research Grant Scheme sponsored by City University of Hong Kong, China (700264). 


\section{REFERENCES}

1. Amblee, N. and Bui, T. Freeware downloads: An empirical investigation into the impact of expert and user review on demand for digital goods. In 13th Amercias Conference on Information Systems, Colorado, USA, 2007.

2. Bach, G.R. Marathon group dynamics: Ii. Dimensons of helpfulness: Therapeutic aggression. Psychological Reports, 20, (1967), 1147-1158.

3. Baek, H.; Ahn, J., and Choi, Y. Helpfulness of online consumer reviews: Reader's objectives and review cues. International Journal of Electronic Commerce, 17, 2 (2012).

4. Bailey, A.A. Consumer awareness and use of product review websites. Journal of Interactive Advertising, 6, 1 (2005), 90-108.

5. Benlian, A.; Titah, R., and Hess, T. Differential effects of provider recommendations and consumer reviews in e-commerce transactions: An experimental study. Journal of Management Information Systems, 29, 1 (2012), 237-272.

6. Borgida, E. and Nisbett, R.E. The differential impact of abstract vs. Concrete information on decisions. Journal of Applied Social Psychology, 7, 3 (1977), 258-271.

7. Buda, R. and Zhang, Y. Consumer product evaluation: The interactive effect of message framing, presentation order, and source credibility. Journal of Product \& Brand Management, 9, 4 (2000), 229-242.

8. Callero, P.L.; Howard, J.A., and Piliavin, J.A. Helping behavior as role behavior: Disclosing social structure and history in the analysis of prosocial action. Social Psychology Quarterly, 50, 3 (1987), 247-256.

9. Cao, Q.; Duan, W., and Gan, Q. Exploring determinants of voting for the "helpfulness" of online user reviews: A text mining approach. Decision Support Systems, 50, (2011), 511521.

10. Cenfetelli, R.T. and Bassellier, G. Interpretation of formative measurement in information systems research. MIS Quarterly, 33, 4 (2009), 689-707.

11. Chaiken, S. Heuristic versus systematic information processing and the use of source versus message cues in persuasion. Journal of Personality and Social Psychology, 39, 5 (1980), 752-766.

12. Chaiken, S. and Maheswaran, D. Heuristic processing can bias systematic processing: Effects of source credibility, argument ambiguity, and task importance on attitude judgment. Journal of Personality and Social Psychology, 66, 3 (1994), 460-473.

13. Chakravarti, A.; Janiszewski, C., and Ulkumen, G. The neglect of prescreening information. Journal of Marketing Research, 43, 4 (2006), 642-653.

14. Cheema, A. and Papatla, P. Relative importance of online versus offline information for internet purchases: Product category and internet experience effects. Journal of Business Research, 63, 9-10 (2010), 979-985.

15. Chen, S.; Duckworth, K., and Chaiken, S. Motivated heuristic and systematic processing. Psychological Inquiry, 10, 1 (1999), 44-49.

16. Cheung, M.Y.; Luo, C.; Sia, C.L., and Chen, H. Credibility of electronic word-of-mouth: Informational and normative determinants of on-line consumer recommendations. International Journal of Electronic Commerce, 13, 4 (2009), 9-38. 
17. Clemons, E.K.; Gao, G.G., and Hitt, L.M. When online reviews meet hyperdifferentiation: A study of the craft beer industry. Journal of Management Information Systems, 23, 2 (2006), 149-171.

18. CNNIC. Annual research report of china's online shopping market. 2012; Available from: http://www.51report.com/research/detail/128090525.html.

19. Connors, L.; Mudambi, S.M., and Schuff, D. Is it the review or the reviewer? A multimethod approach to determine the antecedents of online review helpfulness. In 44th Hawaii International Conference on System Sciences, Hawaii, USA, 2011.

20. Cooper, D.R. and Schindler, P.S. Business research methods (11th ed.): McGraw-Hill/Irwin, 2010.

21. Cui, G.; Lui, H.-K., and Guo, X. The effect of online consumer reviews on new product sales. International Journal of Electronic Commerce, 17, 1 (2012), 39-57.

22. Danescu-Niculescu-Mizil, C.; Kossinets, G.; Kleinberg, J., and Lee, L. How opinions are received by online communities: A case study on amazon.Com helpfulness votes. In 18th International Conference on World Wide Web, Madrid, 2009.

23. DeBono, K.G. and Harnish, R.J. Source expertise, source attractiveness, and the processing of persuasive information: A functional approach. Journal of Personality and Social Psychology, 55, 4 (1988), 541-546.

24. Dellarocas, C.; Gao, G.G., and Narayan, R. Are consumers more likely to contribute online reviews for hit or niche products? Journal of Management Information Systems, 27, 2 (2010), 127-157.

25. Dholakia, R.R. and Sternthal, B. Highly credible sources: Persuasive facilitators or persuasive liabilities? Journal of Consumer Research, 3, 4 (1977), 223-232.

26. Duan, W.; Gu, B., and Whinston, A.B. Do online reviews matter?- an empirical investigation of panel data. Decision Support Systems, 45, 4 (2008), 1007-1016.

27. Eagly, A.H. and Chaiken, S. Cognitive theories of persuasion, 1984.

28. eMarketer. The role of customer product reviews. 2010 [cited 2011 Sep 22nd]; Available from: http://www.emarketer.com/Article.aspx?R=1008019.

29. Forman, C.; Ghose, A., and Wiesenfeld, B. Examining the relationship between reviews and sales: The role of reviewer identity disclosure in electronic markets. Information Systems Research, 19, 3 (2008), 291-313.

30. Ghose, A. and Ipeirotis, P.G. Estimating the helpfulness and economic impact of product reviews: Mining text and reviewer characteristics. IEEE Transactions on Knowledge and Data Engineering, 23, 10 (2010), 1498 - 1512

31. Gist, M.E. Self-efficacy: Implicaitons for organizational behavior and human resource management. Academy of Management Review, 12, 3 (1987), 472-485.

32. Hart-Davidson, W.; McLeod, M.; Klerkx, C., and Wojcik, M. A method for measuring helpfulness in online peer review. In 28th ACM International Conference on Design of Communication, 2010.

33. Haubl, G. and Trifts, V. Consumer decision making in online shopping environments: The effects of interactive decision aids. Marketing Science, 19, 1 (2000), 4-21.

34. Herr, P.M.; Kardes, F.R., and Kim, J. Effects of word-of-mouth and product-attribute information on persuasion: An accessibility-diagnosticity perspective. Journal of Consumer Research, 17, 4 (1991), 454-462. 
35. Hoch, S.J. and Deighton, J. Managing what consumers learn from experience. Journal of Marketing, 53, 2 (1989), 1-20.

36. Hu, N.; Liu, L., and Zhang, J.J. Do online reviews affect product sales? The role of reviewer characteristics and temporal effects. Information Technology Manage, 9, 3 (2008), 201-214.

37. Jain, S.P. and Posavac, S.S. Prepurchase attribute verifiability, source credibility, and persuasion. Journal of Consumer Psychology, 11, 3 (2001), 169-180.

38. Jiang, Y. and Punj, G.N. The effects of attribute concreteness and prominence on selective processing, choice, and search experience. Journal of Academy of Marketing Science, 38, (2010), 471-489.

39. Jiang, Z. and Benbasat, I. The effects of presentation methods and task complexity on online consumers' product understanding. MIS Quarterly, 31, 3 (2007), 475-500.

40. Jiang, Z. and Benbasat, I. Investigating the influence of the functional mechanisms of online product presentations. Information Systems Research, 18, 4 (2007), 454-470.

41. Jin, J. and Liu, Y. How to interpret the helpfulness of online product reviews: Bridging the needs between customers and designers. In 2nd International Workshop on Search and Mining User-Generated Contents, 2010.

42. Kleinmuntz, D.N. and Schkade, D.A. Information displays and decision processes. Psychological Science, 4, 4 (1993), 221-229.

43. Kumar, N. and Benbasat, I. The influence of recommendations and consumer reviews on evaluations of websites. Information Systems Research, 17, 4 (2006), 425-439.

44. Kwon, O. and Sung, Y. Shifting selves and product reviews: How the effects of product reviews vary depending on the self-views and self-regulatory goals of consumers. International Journal of Electronic Commerce, 17, 1 (2012), 59-81.

45. Li, M.; Tan, C.-H.; Wei, K.-K., and Wang, K. Where to place product review? An information search process perspective. In 31st Annual International Conference on Information Systems (ICIS), St. Louis, U.S, 2010.

46. Li, X. and Hitt, L.M. Self-selection and information role of online product reviews. Information Systems Research, 19, 4 (2008), 456-474.

47. Li, X.; Hitt, L.M., and Zhang, Z.J. Product reviews and competition in markets for repeat purchase products. Journal of Management Information Systems, 27, 4 (2011), 9-41.

48. Lim, K.H. and Benbasat, I. The effect of multimedia on perceived equivocality and perceived usefulness of information systems. MIS Quarterly, 24, 3 (2000), 449-471.

49. Manz, C.C. and Sims, H.P.J. Vicarious learning: The influence of modeling on organizational behavior. Academy of Management Review, 6, 1 (1981), 105-113.

50. Meyers-Levy, J. and Maheswaran, D. Exploring message framing outcomes when systematic, heuristic, or both types of processing occur. Journal of Consumer Psychology, 14,1 \& 2 (2004), 159-167.

51. Mudambi, S.M. and Schuff, D. What makes a helpful online review? A study of customer reviews on amazon.Com. MIS Quarterly, 34, 1 (2010), 185-200.

52. Otterbacher, J. "Helpfulness" in online communities: A measure of message quality. In 27th International Conference on Human Factors in Computing Systems, Boston, USA, 2009.

53. Pan, Y. and Zhang, J.Q. Born unequal: A study of the helpfulness of user-generated product reviews. Journal of Retailing, 87, 4 (2011), 598-612. 
54. Park, D.-H.; Lee, J., and Han, I. The effect of online consumer reviews on consumer purchasing intention: The moderating role of involvement. International Journal of Electronic Commerce, 11, 4 (2007), 125-148.

55. Pavlou, P. and Fygenson, M. Understanding and predicting electronic commerce adoption: An extension of the theory of planned behavior. MIS Quarterly, 30, 1 (2006), 115-143.

56. Pavlou, P.; Liang, H., and Xue, Y. Uncertainty and mitigating uncertainty in online exchange relationships: A principal-agent perspective. MIS Quarterly, 31, 1 (2007), 105-131.

57. Pavlou, P.A. and Sawy, O.A.E. From it leveraging competence to competitive advantage in turbulent environments: The case of new product development. Information Systems Research, 17, 3 (2006), 198-227.

58. Petter, S.; Straub, D., and Rai, A. Specifying formative constructs in information systems research. MIS Quarterly, 31, 4 (2007), 623-656.

59. Petty, R.E. and Cacioppo, J.T. The elaboration likelihood model of persuasion. Advances in Experimental Social Psychology, 19, 1 (1986), 123-205.

60. Riegner, C. Word of mouth on the web: The impact of web 2.0 on consumer purchase decisions. Journal of Advertising Research, 47, 4 (2007), 436-449.

61. Sasaki, T.; Becker, D.V.; Janssen, M.A., and Neel, R. Does greater product information actually inform consumer decisions? The relationship between product information quantity and diversity of consumer decisions. Journal of Economic Psychology, 32, 3 (2011), 391398.

62. Schindler, R.M. and Bickart, B. Perceived helpfulness of online consumer reviews: The role of message content and style. Journal of Consumer Behaviour, 11, 3 (2012), 234-243.

63. Semin, G.R. Language puzzles: A prospective retrospective on the linguistic category model. Journal of Language and Social Psychology, 27, 2 (2008), 197-209.

64. Semin, G.R. and Fiedler, K. The cognitive functions of linguistic categories in describing persons: Social cognition and language. Journal of personality and social psychology, 54, 4 (1988), 558-568.

65. Sen, S. and Lerman, D. Why are you telling me this? An examination into negative consumer reviews on the web. Journal of Interactive Marketing, 21, 4 (2007), 76-96.

66. Shafir, E.; Simonson, I., and Tversky, A. Reason-based choice. Special issue: Reasoning and decision making. Cognition, 49, 2 (1993), 11-36.

67. Shin, B. and Kim, G. Investigating the reliability of second-order formative measurement in information systems research. European Journal of Information Systems, 20, (2011), 608623.

68. Smith, S.P.; Johnston, R.B., and Howard, S. Vicarious experience in retail e-commerce: An inductive taxonomy of product evaluation support features. Information Systems and eBusiness Management, 3, (2005), 21-46.

69. Stern, B. A revised communication model for advertising: Multiple dimensions of the source , message, and the recipient. Journal of Advertising, 23, 2 (1994), 5-15.

70. Tan, C.H.; Teo, H.H., and Benbasat, I. Assessing screening and evaluation decision support systems: A resource-matching approach. Information Systems Research, 21, 2 (2010), 305326.

71. Tsur, O. and Rappoport, A. Revrank: A fully unsupervised algorithm for selecting the most helpful book reviews. 2009. 
72. Wasko, M.M. and Faraj, S. Why should i share? Examining social capital and knowledge contribution in electronic networks of practice. MIS Quarterly, 29, 1 (2005), 35-57.

73. Wilson, E.J. and Sherrell, D.L. Source effects in communication and persuasion research: A meta-analysis of effect size. Journal of Academy of Marketing Science, 21, 2 (1993), 101112.

74. Wood, S.L. and Lynch, J.G. Prior knowledge and complacency in new product learning. Journal of Consumer Research, 29, 3 (2002), 416-426.

75. Xiong, W. and Litman, D. Understanding differences in perceived peer-review helpfulness using natural language processing. In 6th Workshop on Innovative Use of NLP for Building Educational Applications, Portland, 2011.

76. Zhu, L.; Benbasat, I., and Jiang, Z. Let's shop online together: An empirical investigation of collaborative online shopping support. Information Systems Research, 21, 4 (2010), 872-891. 
Table 1 . The design of the treatment groups

\begin{tabular}{|c|c|c|}
\hline & Expert-written & Customer-written \\
\hline Abstract & Group 1 & Group 2 \\
\hline Concrete & Group 3 & Group 4 \\
\hline
\end{tabular}

\begin{tabular}{|c|c|l|}
\hline \multicolumn{2}{|c|}{ Table 2. The operationalization of the dimensions of product review helpfulness } \\
\hline Dimension & Measures & \multicolumn{1}{c|}{ Source } \\
\hline Perceived source credibility & $\begin{array}{c}\text { Subjective } \\
\text { measures }\end{array}$ & $\begin{array}{l}\text { Adopted from [16], changes have been } \\
\text { made for contextualization. }\end{array}$ \\
\hline $\begin{array}{c}\text { Perceived content } \\
\text { diagnosticity }\end{array}$ & $\begin{array}{c}\text { Subjective } \\
\text { measures }\end{array}$ & $\begin{array}{l}\text { Adopted from [39], changes have been } \\
\text { made for contextualization. }\end{array}$ \\
\hline Perceived vicarious expression & $\begin{array}{c}\text { Subjective } \\
\text { measures }\end{array}$ & $\begin{array}{l}\text { Adopted from [49], sufficient changes } \\
\text { have been made for contextualization. }\end{array}$ \\
\hline
\end{tabular}

\begin{tabular}{|l|c|c|c|c|}
\hline Table 3. The correlation between the dimensions \\
\hline & AVE & 1 & 2 & 3 \\
\hline Perceived source credibility & .79 & $\mathbf{. 8 8}$ & & \\
\hline Perceived content diagnosticity & .82 & $.47^{* *}$ & $\mathbf{. 9 1}$ & \\
\hline Perceived vicarious expression & .82 & $.43^{* *}$ & $.60^{* *}$ & $\mathbf{. 9 1}$ \\
\hline
\end{tabular}

Note: ${ }^{* *} \mathrm{p}<.05$; the values in the diagonal are the square root of the AVE value.

\begin{tabular}{|c|l|l|l|}
\hline Table 4. Factor loading & \multicolumn{3}{l|}{} \\
\hline & 1 & 2 & 3 \\
\hline cd 1 & .91 & .42 & .55 \\
\hline cd 2 & .90 & .44 & .54 \\
\hline cd 3 & .90 & .41 & .54 \\
\hline sc 1 & .84 & .41 \\
\hline sc 2 & .44 & .38 \\
\hline sc 3 & .39 & .99 & .36 \\
\hline ve 1 & .41 & .39 & .88 \\
\hline ve 3 & .63 & .41 & .93 \\
\hline
\end{tabular}

\begin{tabular}{|l|l|l|l|l|}
\hline Table 5. The bivariate correlation between dimension and construct \\
\hline & 1 & 2 & 3 & 4 \\
\hline Perceived source credibility & 1.00 & & & \\
\hline Perceived content diagnosticity & $.47^{* * *}$ & 1.00 & & \\
\hline Perceived vicarious expression & $.43^{* * *}$ & $.60^{* * *}$ & 1.00 & \\
\hline Perceived review helpfulness & $.77^{* * *}$ & $.85^{* * *}$ & $.83^{* * *}$ & 1.00 \\
\hline
\end{tabular}

Note: $* * * \mathrm{p}<.01$; in this table, we have included the perceived review helpfulness because we formulate a reflective-formative second order measurement of review helpfulness. As [66] indicated, before proceeding the formative measure assessment, we need to evaluate the construct validity of the first-order reflective indicators. Acceptable construct validity should be granted. In this regard, we examined the convergent validity and discriminant validity of the first-order reflective indicators. All the results indicate acceptable construct validity. 


\section{Table 6. The mean values of product review helpfulness}

Abstract Customer (written)

$4.15(.83)$
Abstract Expert

(written)

$4.06(.70)$
Concrete Customer (written)

$4.94(.91)$
Concrete Expert (written) $4.44(.79)$

\section{Table 7. Univariate (ANCOVA) tests}

Source

Manipulated variable

Authorship of product review (Authorship; from customer or from $\quad$ F $=\mathbf{9 . 4 9 * * *}$ expert)

Content abstractness of product review (Abstractness; abstract or concrete)

Authorship*Abstractness

$\mathrm{F}=33.28 * * *$

Controlled variable

Online shopping experience

Product review helpfulness

Prior product knowledge

Duration of the experiment

Note: ${ }^{* *} \mathrm{p}<.05 ; * * * \mathrm{p}<.01$

Table 8. Hypothesis testing for the interaction effect

Content abstractness

\begin{tabular}{|c|c|c|c|}
\hline Content abstractness & Source & $\begin{array}{l}\text { Mean of the product review } \\
\text { helpfulness }\end{array}$ & $\mathrm{T}$ value \\
\hline \multirow[t]{2}{*}{ Abstract } & Expert & 4.06 & \multirow[t]{2}{*}{0.68} \\
\hline & Customer & 4.15 & \\
\hline \multirow[t]{2}{*}{ Concrete } & Expert & 4.44 & \multirow[t]{2}{*}{$3.26 * * *$} \\
\hline & Customer & 4.94 & \\
\hline
\end{tabular}

Note: *** $\mathrm{p}<.01$

$$
\mathbf{F}=4.99 * *
$$

$$
\mathrm{F}=1.35
$$

$\mathrm{F}=10.54 * * *$

$\mathrm{F}=10.22 * * *$ 


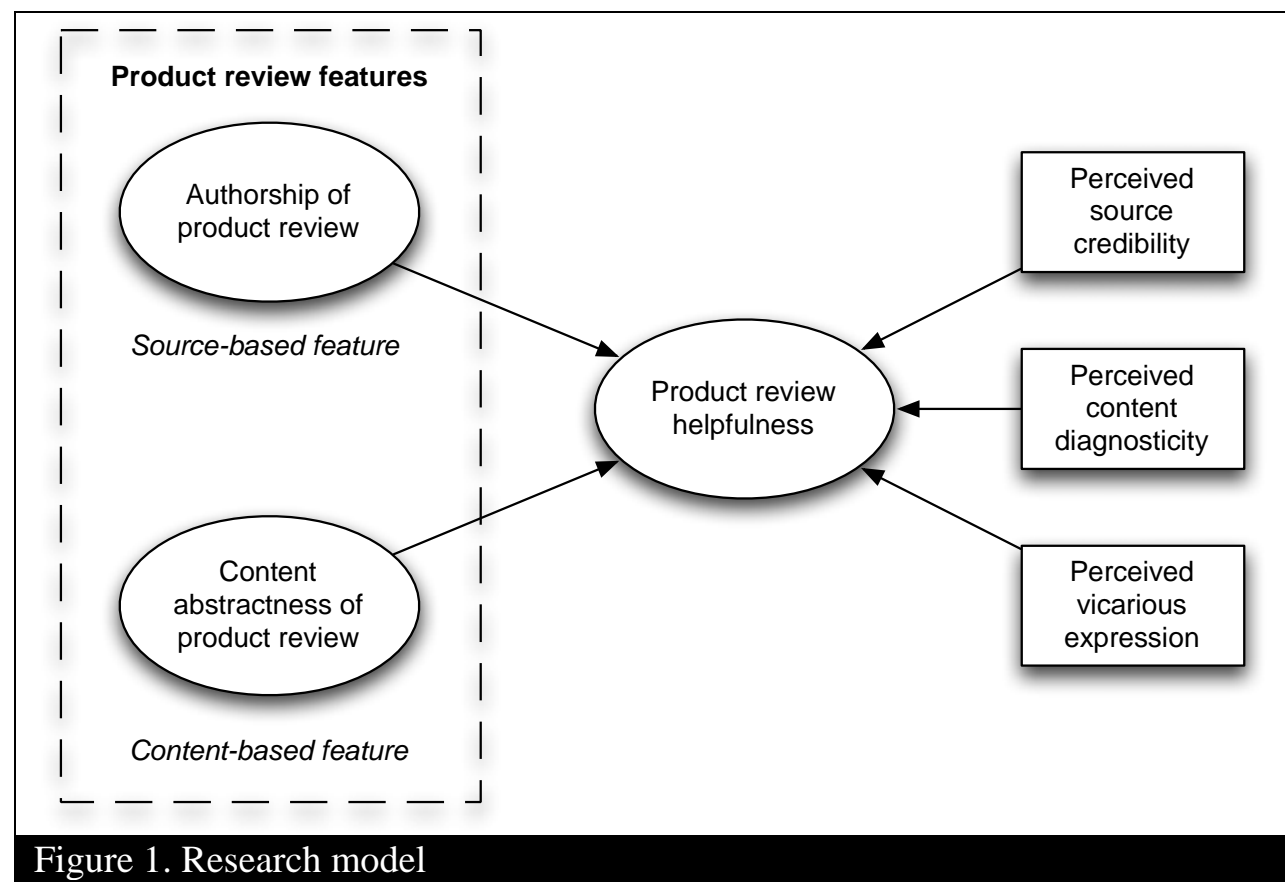

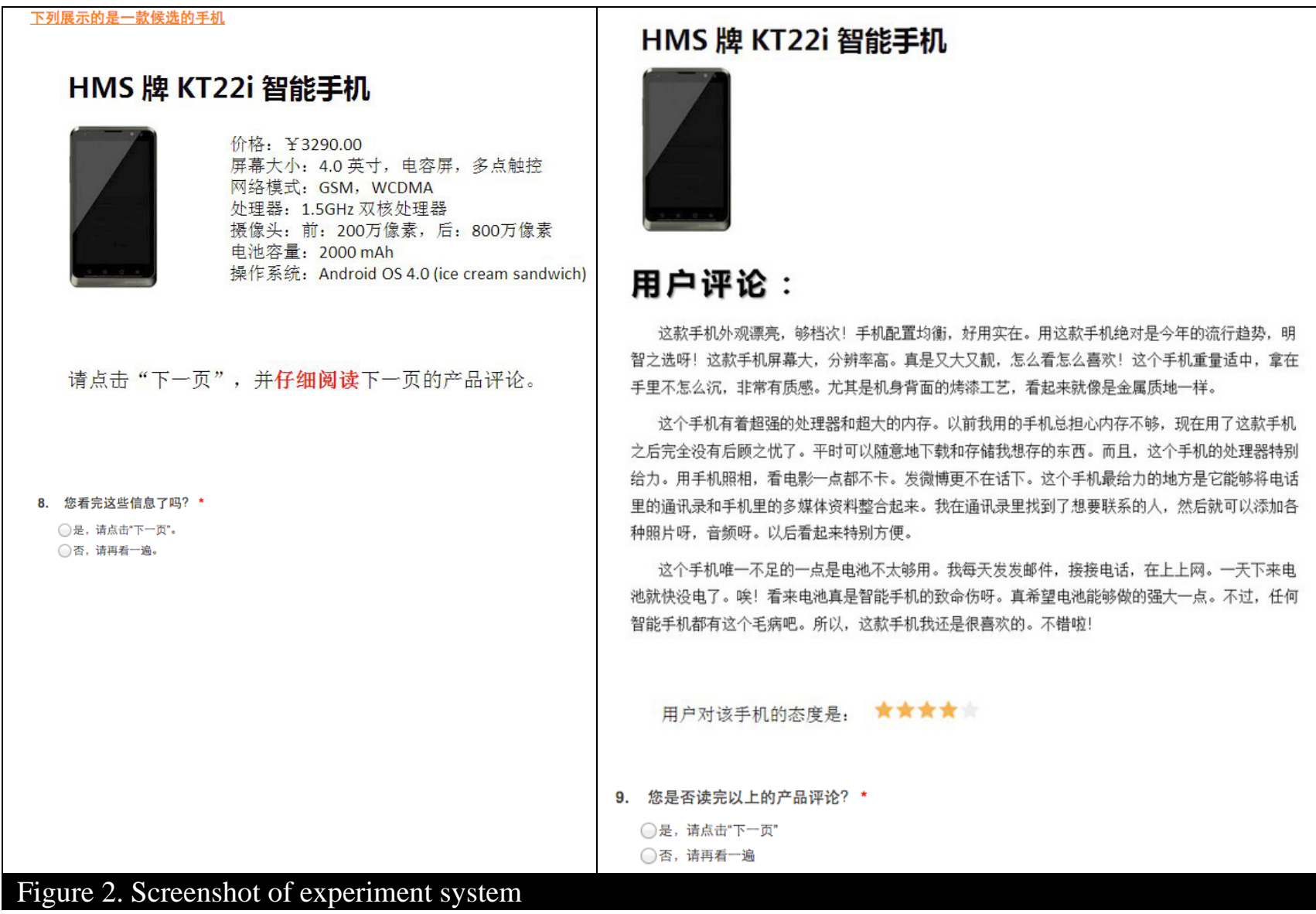



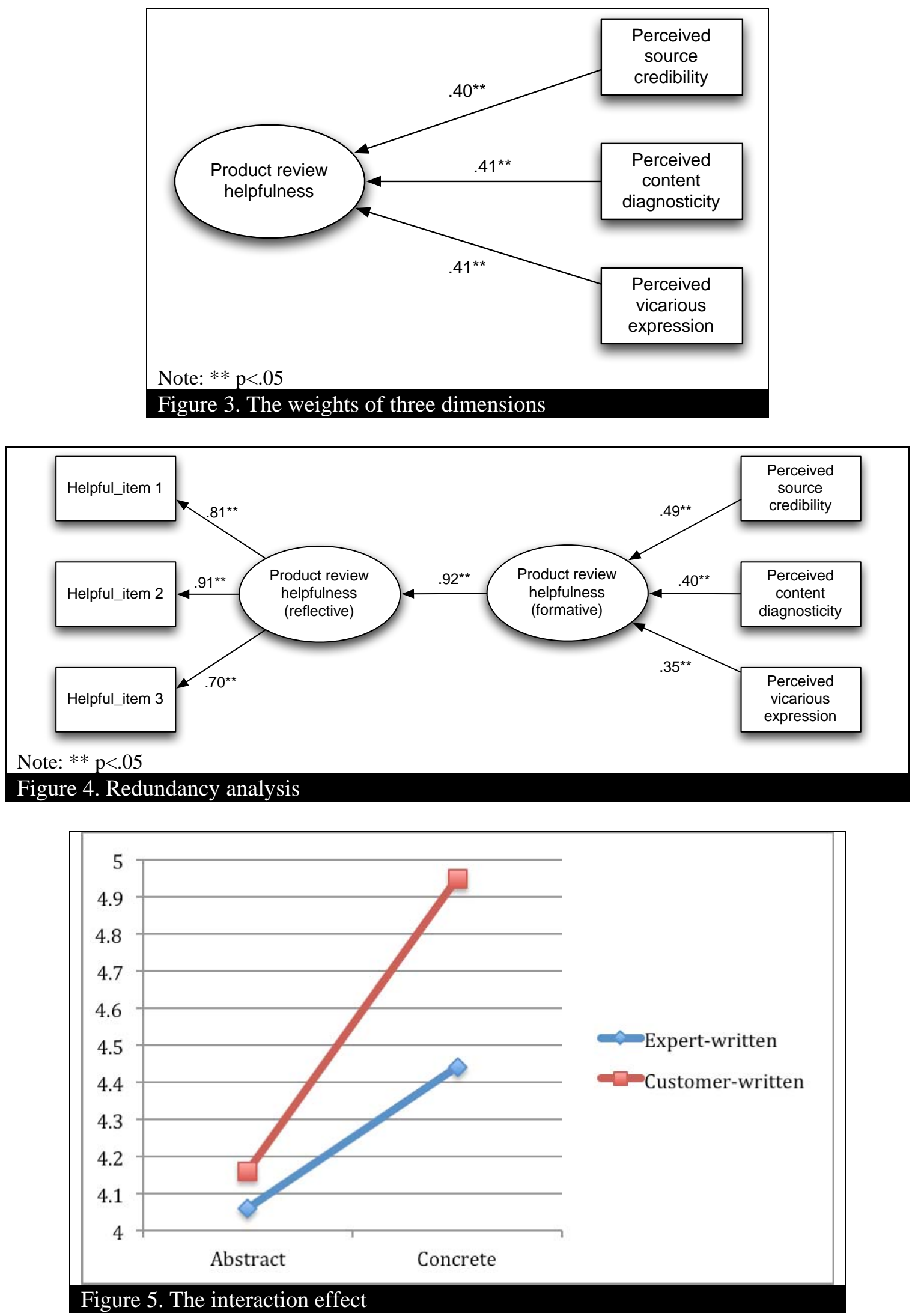


\section{Appendix A: Summary of prior works}

\begin{tabular}{|c|c|c|c|c|c|}
\hline Paper & $\begin{array}{l}\text { Research } \\
\text { field }\end{array}$ & Methodology & $\begin{array}{l}\text { Theoretical } \\
\text { underpinning }\end{array}$ & Description & Outcomes \\
\hline \multicolumn{6}{|c|}{ 1. Different perspectives for assessing the product review helpfulness } \\
\hline \multicolumn{6}{|c|}{$\begin{array}{l}\text { 1.a. Source-based feature perspective for assessing product review helpfulness (This field of study focuses on identifying the source-based } \\
\text { features of a product review that could potentially influence its helpfulness) }\end{array}$} \\
\hline [22] & $\begin{array}{l}\text { Computer } \\
\text { sciences }\end{array}$ & $\begin{array}{l}\text { Analytical } \\
\text { modeling }\end{array}$ & No specific theory & $\begin{array}{l}\text { Examined the helpfulness } \\
\text { voting features of a product } \\
\text { review in Amazon.com. }\end{array}$ & $\begin{array}{l}\text { The perceived helpfulness of a } \\
\text { product review depended not only } \\
\text { on its content but also on how in } \\
\text { subtle ways the expressed evaluation } \\
\text { relates to other evaluations of the } \\
\text { same product. }\end{array}$ \\
\hline [29] & $\begin{array}{l}\text { Information } \\
\text { systems }\end{array}$ & $\begin{array}{l}\text { Analytical } \\
\text { modeling }\end{array}$ & $\begin{array}{l}\text { Generic theoretical } \\
\text { underpinning from } \\
\text { information processing }\end{array}$ & $\begin{array}{l}\text { Examined the relationship } \\
\text { between reviews and sales. } \\
\text { Specifically, it investigated } \\
\text { the impact of disclosure of } \\
\text { identity-description } \\
\text { information used in the } \\
\text { product review on the } \\
\text { evaluation of the } \\
\text { helpfulness of online } \\
\text { reviews and purchase } \\
\text { decisions. }\end{array}$ & $\begin{array}{l}\text { The disclosure of reviewer identity- } \\
\text { descriptive information can be used } \\
\text { to supplement or replace product } \\
\text { information when making purchase } \\
\text { decisions and evaluating the } \\
\text { helpfulness of online reviews. } \\
\text { Reviews containing more positive } \\
\text { identity descriptive information and } \\
\text { the prevalence of reviewer } \\
\text { disclosure of identity information } \\
\text { are associated with increases in } \\
\text { subsequent online product sales. }\end{array}$ \\
\hline [7] & Marketing & $\begin{array}{l}\text { Laboratory } \\
\text { experiment }\end{array}$ & $\begin{array}{l}\text { Generic psychology } \\
\text { theories }\end{array}$ & $\begin{array}{l}\text { Examined the impact of } \\
\text { presentation order, source } \\
\text { credibility, and message } \\
\text { framing on the evaluation } \\
\text { of product attributes. }\end{array}$ & $\begin{array}{l}\text { Framing had a significant influence } \\
\text { on consumer decision-making. The } \\
\text { results were more encouraging for } \\
\text { presentation order than they were for } \\
\text { source credibility. However, one } \\
\text { should not completely discount } \\
\text { source credibility, because the three- } \\
\text { way interaction suggested that } \\
\text { customers considered the source as a }\end{array}$ \\
\hline
\end{tabular}




\begin{tabular}{|c|c|c|c|c|c|}
\hline & & & & & $\begin{array}{l}\text { viable influence on their product } \\
\text { attitudes when message framing and } \\
\text { message order were considered } \\
\text { simultaneously. }\end{array}$ \\
\hline [23] & $\begin{array}{l}\text { Consumer } \\
\text { psychology }\end{array}$ & Experiment & $\begin{array}{l}\text { Generic psychology } \\
\text { theories }\end{array}$ & $\begin{array}{l}\text { Investigated the interaction } \\
\text { of source expertise, source } \\
\text { attractiveness, and the } \\
\text { perceived persuasion of } \\
\text { message. }\end{array}$ & $\begin{array}{l}\text { High self-monitoring individuals } \\
\text { were systematically processing the } \\
\text { attractive source's messages and } \\
\text { were heuristically processing the } \\
\text { expert source's message. Conversely, } \\
\text { low self-monitoring individuals were } \\
\text { systematically processing the expert } \\
\text { source's message and were } \\
\text { heuristically processing the } \\
\text { attractive source’s messages. }\end{array}$ \\
\hline [25] & $\begin{array}{l}\text { Consumer } \\
\text { behavior }\end{array}$ & Experiment & $\begin{array}{l}\text { Self-perception theory, } \\
\text { cognitive response } \\
\text { analysis }\end{array}$ & $\begin{array}{l}\text { Investigated the impact of } \\
\text { the communicator attributes } \\
\text { of character on the } \\
\text { persuasiveness of the } \\
\text { information. }\end{array}$ & $\begin{array}{l}\text { When only the source and } \\
\text { communication related cues are } \\
\text { available, cognitive response } \\
\text { analysis may be employed to predict } \\
\text { that highly credible sources will be } \\
\text { more persuasive than or as } \\
\text { persuasive as low credibility } \\
\text { communicators. By contrast, when } \\
\text { the behavior of an individual as well } \\
\text { as source and message cues are } \\
\text { available, the self-perception theory } \\
\text { can be employed to predict that a } \\
\text { low credibility source will be more } \\
\text { persuasive than highly credible ones. }\end{array}$ \\
\hline \multicolumn{6}{|c|}{$\begin{array}{l}\text { 1.b. Content-based feature perspective for assessing product review helpfulness (This category of studies focused on identifying the } \\
\text { content-based features of a product review that would influence product review helpfulness, except in the study by Jiang et al. } 2007 \mathrm{~b} \text {, which } \\
\text { introduced the concept of diagnosticity to the product-related research field) }\end{array}$} \\
\hline [62] & $\begin{array}{l}\text { Consumer } \\
\text { behavior }\end{array}$ & $\begin{array}{l}\text { Quasi- } \\
\text { experiment }\end{array}$ & $\begin{array}{l}\text { Generic psychology } \\
\text { theories }\end{array}$ & $\begin{array}{l}\text { Examined the impact of the } \\
\text { content and style factors of } \\
\text { product reviews on the } \\
\text { evaluation of helpfulness of }\end{array}$ & $\begin{array}{l}\text { Several observations were made. } \\
\text { First, the length of a product review } \\
\text { is positively related to its perceived } \\
\text { value to other consumers but only up }\end{array}$ \\
\hline
\end{tabular}




\begin{tabular}{|c|c|c|c|c|c|}
\hline & & & & $\begin{array}{l}\text { a product review. The } \\
\text { content factors included } \\
\text { number of statements in a } \\
\text { review, valence of a } \\
\text { product review, product- } \\
\text { descriptive statements, and } \\
\text { reviewer-descriptive } \\
\text { statements; the style factors } \\
\text { included the factors related } \\
\text { to weaker and strong } \\
\text { impacts, such as grammar, } \\
\text { spelling, and so on. }\end{array}$ & $\begin{array}{l}\text { to a certain point. Second, WOM } \\
\text { recipients require enough } \\
\text { information to make an informed } \\
\text { decision but only up to a certain } \\
\text { point. Third, review value is } \\
\text { positively related to a moderate } \\
\text { proportion of positive evaluative } \\
\text { statements. Fourth, a higher } \\
\text { proportion of product-descriptive } \\
\text { statements are related to review } \\
\text { value. }\end{array}$ \\
\hline [51] & $\begin{array}{l}\text { Information } \\
\text { systems }\end{array}$ & $\begin{array}{l}\text { Analytical } \\
\text { modeling }\end{array}$ & $\begin{array}{l}\text { Paradigm of search and } \\
\text { experience goods from } \\
\text { information economics }\end{array}$ & $\begin{array}{l}\text { Investigated the constructs } \\
\text { that manifested the } \\
\text { helpfulness of online } \\
\text { product review using the } \\
\text { analytical modeling } \\
\text { approach and secondary } \\
\text { archive data. }\end{array}$ & $\begin{array}{l}\text { The product type moderates the } \\
\text { effect of review extremity on the } \\
\text { helpfulness of the review. For } \\
\text { experience goods, reviews with } \\
\text { extreme ratings are less helpful than } \\
\text { reviews with moderate ratings. For } \\
\text { both product types, review depth has } \\
\text { a positive effect on the helpfulness } \\
\text { of the review, but the product type } \\
\text { moderates the effect of review depth } \\
\text { on the helpfulness of the review. } \\
\text { Review depth has a greater positive } \\
\text { effect on the helpfulness of the } \\
\text { review for search goods than for } \\
\text { experience goods. }\end{array}$ \\
\hline [40] & $\begin{array}{l}\text { Information } \\
\text { systems }\end{array}$ & Experiment & $\begin{array}{l}\text { General psychology } \\
\text { theories }\end{array}$ & $\begin{array}{l}\text { Investigated the functional } \\
\text { mechanisms that influence } \\
\text { consumer intentions to } \\
\text { return to a website and their } \\
\text { intentions to purchase. }\end{array}$ & $\begin{array}{l}\text { Vividness and interactivity of } \\
\text { product presentations are the } \\
\text { primary design features that } \\
\text { influence the efficacy of the } \\
\text { presentations. Consumer perceptions } \\
\text { of the diagnosticity of websites, of } \\
\text { compatibility between online and } \\
\text { physical shopping, and shopping }\end{array}$ \\
\hline
\end{tabular}




\begin{tabular}{|c|c|c|c|c|c|}
\hline & & & & & $\begin{array}{l}\text { enjoyment all influence consumer } \\
\text { attitudes toward online shopping. }\end{array}$ \\
\hline [65] & Marketing & Experiment & $\begin{array}{l}\text { Generic psychology } \\
\text { theories }\end{array}$ & $\begin{array}{l}\text { Investigated how the } \\
\text { consumers evaluate the } \\
\text { usefulness of both the } \\
\text { positive and negative } \\
\text { product reviews. }\end{array}$ & $\begin{array}{l}\text { Product type moderates the effect of } \\
\text { review valence, and readers exhibit a } \\
\text { negative bias only for utilitarian } \\
\text { product reviews. Furthermore, } \\
\text { reader attributions on the } \\
\text { motivations of the reviewer mediate } \\
\text { the effect of this moderation on their } \\
\text { attitudes toward a review. Compared } \\
\text { with the utilitarian product, readers } \\
\text { of negative hedonic product reviews } \\
\text { are more likely to attribute the } \\
\text { negative opinion expressed to the } \\
\text { reviewer's internal reasons and the } \\
\text { utilitarian product for the external } \\
\text { reasons of the reviewers. }\end{array}$ \\
\hline \multicolumn{6}{|c|}{$\begin{array}{l}\text { 2. Nature of the product review helpfulness [This stream of research focuses on gaining a better understanding of the types of product } \\
\text { reviews that could be perceived helpful. Some content-related and non-content-related factors (expertise, style, and so on) are explored to } \\
\text { determine whether or not a product review is perceived as helpful] }\end{array}$} \\
\hline [19] & $\begin{array}{l}\text { Information } \\
\text { systems }\end{array}$ & $\begin{array}{l}\text { Laboratory } \\
\text { experiment }\end{array}$ & No specific theory & $\begin{array}{l}\text { Examined the basic } \\
\text { elements of the helpfulness } \\
\text { of a product review and } \\
\text { identified } 18 \text { factors that } \\
\text { might enhance the } \\
\text { helpfulness of a product } \\
\text { review. This paper also } \\
\text { examined three major } \\
\text { factors associated with the } \\
\text { helpfulness of a product } \\
\text { review. }\end{array}$ & $\begin{array}{l}\text { Review balance does not appear to } \\
\text { affect review helpfulness; the self- } \\
\text { stated expertise of a reviewer has a } \\
\text { positive influence on the perceived } \\
\text { helpfulness of a review; the } \\
\text { perceived similarity of the reviewer } \\
\text { to the reader apparently does not } \\
\text { influence the helpfulness of a } \\
\text { product review; product domain } \\
\text { knowledge can affect perception of } \\
\text { review helpfulness. }\end{array}$ \\
\hline [53] & $\begin{array}{l}\text { Consumer } \\
\text { behavior }\end{array}$ & $\begin{array}{l}\text { Analytical } \\
\text { modeling }\end{array}$ & No specific theory & $\begin{array}{l}\text { Provided an analysis of the } \\
\text { determinants of product } \\
\text { review helpfulness. } \\
\text { Examined the effects of }\end{array}$ & $\begin{array}{l}\text { Both review valence and length have } \\
\text { positive effects on product review } \\
\text { helpfulness, but the product type } \\
\text { moderates these effects. Compared }\end{array}$ \\
\hline
\end{tabular}




\begin{tabular}{|l|l|l|l|l|}
\hline & & & $\begin{array}{l}\text { review characteristics, } \\
\text { product type, and reviewer } \\
\text { characteristics on perceived } \\
\text { product review helpfulness. }\end{array}$ & $\begin{array}{l}\text { with utilitarian products, experiential } \\
\text { products lead to a decreased efficacy } \\
\text { in the evaluation of product review } \\
\text { helpfulness. }\end{array}$ \\
\hline$[52]$ & HCI & $\begin{array}{l}\text { Analytical } \\
\text { modeling }\end{array}$ & $\begin{array}{l}\text { No specific theory } \\
\text { "xamined the nature of } \\
\text { relpfulness" of online } \\
\text { reviews. This paper adopted } \\
\text { a well-established } \\
\text { framework for assessing } \\
\text { data quality and analyzed } \\
\text { can be manifested by topical } \\
\text { relevancy, ease of understanding, } \\
\text { believability, and objectivity. } \\
\text { Amazon.com. Finally, a } \\
\text { correlation and regression } \\
\text { analysis confirmed these } \\
\text { key components. }\end{array}$ \\
\hline
\end{tabular}

3. Evaluation of product review helpfulness (This stream of studies concentrates on defining criteria to evaluate the helpfulness of a product review. Product reviews with source-related, content-related, context-related, and timeliness-related criteria are explored to evaluate product review helpfulness)

\begin{tabular}{|l|l|l|l|l|l|}
\hline [32] & $\begin{array}{l}\text { Computer } \\
\text { sciences } \\
\text { modeling }\end{array}$ & $\begin{array}{l}\text { No specific theory } \\
\text { Analytical }\end{array}$ & $\begin{array}{l}\text { Described an original } \\
\text { method for evaluating peer } \\
\text { review in online systems by } \\
\text { calculating the helpfulness } \\
\text { of an online review. This } \\
\text { paper regarded the } \\
\text { helpfulness of the online } \\
\text { review as the quality of that } \\
\text { online review. }\end{array}$ & $\begin{array}{l}\text { This paper proposed a new way to } \\
\text { measure the helpfulness of online } \\
\text { beens. It included several } \\
\text { helpfulness of reviews or reviewer } \\
\text { responses to instructor-specified } \\
\text { criteria as follows: (1) rating of } \\
\text { suggestions and comments by the } \\
\text { writer of texts being reviewed, (2) } \\
\text { number of suggestions and } \\
\text { comments the writers add to their } \\
\text { revision strategy, (3) placement of } \\
\text { suggestions in writer revision } \\
\text { strategy, (4) instructor endorsement } \\
\text { of criteria responses, (5) instructor } \\
\text { endorsement of comments and } \\
\text { suggestions, (6) and use of }\end{array}$ \\
\hline
\end{tabular}




\begin{tabular}{|c|c|c|c|c|c|}
\hline & & & & & $\begin{array}{l}\text { comments or suggestions by a writer } \\
\text { in a new version of text ( } 7) \text {. The } \\
\text { weights of each factor were } \\
\text { presented in the brackets followed } \\
\text { by each of the factors. }\end{array}$ \\
\hline [41] & $\begin{array}{l}\text { Computer } \\
\text { sciences }\end{array}$ & $\begin{array}{l}\text { Analytical } \\
\text { modeling }\end{array}$ & No specific theory & $\begin{array}{l}\text { Designed to build the } \\
\text { connection between online } \\
\text { consumer voting and } \\
\text { designer ratings and } \\
\text { predicting the helpfulness } \\
\text { of online reviews based on } \\
\text { review content. }\end{array}$ & $\begin{array}{l}\text { This paper proposed a map to } \\
\text { express product designer ratings } \\
\text { with online helpfulness voting. } \\
\text { After, the authors proposed the } \\
\text { utilization of a regression algorithm } \\
\text { to predict the product review } \\
\text { helpfulness. The regression } \\
\text { algorithm incorporated information } \\
\text { accuracy, information timeliness, } \\
\text { information comparability, } \\
\text { information coverage, and } \\
\text { information relevance. }\end{array}$ \\
\hline [3] & $\begin{array}{l}\text { Information } \\
\text { Systems }\end{array}$ & $\begin{array}{l}\text { Analytical } \\
\text { modeling }\end{array}$ & Dual process theory & $\begin{array}{l}\text { Designed to identify the } \\
\text { antecedents of review } \\
\text { helpfulness from central } \\
\text { and peripheral routes }\end{array}$ & $\begin{array}{l}\text { The results of the paper find that } \\
\text { both the peripheral cues (the review } \\
\text { rating and reviewer's credibility) } \\
\text { and the central cues (review content) } \\
\text { significantly influence the review } \\
\text { helpfulness evaluations. And, the } \\
\text { product type reviews describe partly } \\
\text { moderates the relationship between } \\
\text { the antecedents and the review } \\
\text { helpfulness. }\end{array}$ \\
\hline \multicolumn{6}{|c|}{ 4. Other empirical studies on product review } \\
\hline [21] & $\begin{array}{l}\text { Information } \\
\text { systems }\end{array}$ & $\begin{array}{l}\text { Empirical } \\
\text { study }\end{array}$ & $\begin{array}{l}\text { Innovation diffusion } \\
\text { theory }\end{array}$ & $\begin{array}{l}\text { Analyzed the panel data } \\
\text { from Amazon.com to } \\
\text { evaluate the impact of } \\
\text { consumer review on new } \\
\text { product sales. }\end{array}$ & $\begin{array}{l}\text { This paper has several findings. } \\
\text { First, by differentiating search } \\
\text { product and experience product, this } \\
\text { paper finds the valence of product } \\
\text { review and the page views have } \\
\text { significant impact on the sales of } \\
\text { search product. For the experience }\end{array}$ \\
\hline
\end{tabular}




\begin{tabular}{|c|c|c|c|c|c|}
\hline & & & & & $\begin{array}{l}\text { product, the volume of reviews has } \\
\text { significant impact. However, such } \\
\text { influence is decreased with the } \\
\text { elapse of time. }\end{array}$ \\
\hline [44] & $\begin{array}{l}\text { Information } \\
\text { systems }\end{array}$ & Experiment & Regulatory focus theory & $\begin{array}{l}\text { With two experiments, this } \\
\text { paper examined the } \\
\text { consumers' self-regulatory } \\
\text { goals and its impact on the } \\
\text { processing of information } \\
\text { in the product reviews. }\end{array}$ & $\begin{array}{l}\text { This paper found the fit between } \\
\text { consumer-written product review } \\
\text { and the consumers' dominant self- } \\
\text { construal regulatory goal can } \\
\text { enhance the evaluation of the } \\
\text { product reviews. }\end{array}$ \\
\hline [47] & $\begin{array}{l}\text { Information } \\
\text { systems }\end{array}$ & $\begin{array}{l}\text { Analytical } \\
\text { modeling }\end{array}$ & No specific theory & $\begin{array}{l}\text { Examined the relationship } \\
\text { between the online review } \\
\text { and the pricing strategy of } \\
\text { the repeat purchase } \\
\text { products. }\end{array}$ & $\begin{array}{l}\text { This paper found the online review } \\
\text { may not always benefit the firm } \\
\text { sales performance. Although the } \\
\text { online review could reduce } \\
\text { consumers' uncertainty and enhance } \\
\text { the sales, it could compromise the } \\
\text { sales performance of repeat purchase } \\
\text { product by altering consumers' } \\
\text { propensity to switch among } \\
\text { products. A S-shaped relationship } \\
\text { was found between the quality of } \\
\text { reviews and firm profits. }\end{array}$ \\
\hline [5] & $\begin{array}{l}\text { Information } \\
\text { systems }\end{array}$ & Experiment & No specific theory & $\begin{array}{l}\text { Examined the different } \\
\text { sources of online product } \\
\text { recommendations (provider } \\
\text { recommendation and } \\
\text { consumer review) and the } \\
\text { impact on the consumer } \\
\text { beliefs. }\end{array}$ & $\begin{array}{l}\text { This paper found the provider } \\
\text { recommendations have different } \\
\text { impact on the consumer beliefs and } \\
\text { behavior than consumer review. The } \\
\text { provider recommendation performs } \\
\text { well on the perceived usefulness and } \\
\text { perceived ease of use. The consumer } \\
\text { review is best on the trusting beliefs } \\
\text { and perceived affective quality. }\end{array}$ \\
\hline [17] & $\begin{array}{l}\text { Information } \\
\text { systems }\end{array}$ & $\begin{array}{l}\text { Analytical } \\
\text { modeling }\end{array}$ & $\begin{array}{l}\text { Theories of } \\
\text { hyperdifferentiation and } \\
\text { resonance marketing }\end{array}$ & $\begin{array}{l}\text { Examined the impact of } \\
\text { online review on the } \\
\text { relationship between } \\
\text { product hyperdifferentation }\end{array}$ & $\begin{array}{l}\text { This paper found the online review } \\
\text { could inform consumers about the } \\
\text { product. This effort could influence } \\
\text { companies' product }\end{array}$ \\
\hline
\end{tabular}




\begin{tabular}{|l|l|l|l|l|l|}
\hline & & & & and resonance marketing. & $\begin{array}{l}\text { hyperdifferentiation strategy and the } \\
\text { resonance marketing. In particular, } \\
\text { this paper found the variance of the } \\
\text { valence and the most positive review } \\
\text { could significantly determine the } \\
\text { sales of new product. }\end{array}$ \\
\hline$[24]$ & $\begin{array}{l}\text { Information } \\
\text { systems }\end{array}$ & $\begin{array}{l}\text { Analytical } \\
\text { modeling }\end{array}$ & No specific theory & $\begin{array}{l}\text { Investigated what type of } \\
\text { product the online reviews } \\
\text { comment for. }\end{array}$ & $\begin{array}{l}\text { This paper found the consumer } \\
\text { reviews have two major categories } \\
\text { of the comments. One category } \\
\text { focuses on the less available and less } \\
\text { successful product; The other } \\
\text { category focuses on the most } \\
\text { commented product. This result lead } \\
\text { to a U-shaped relationship of the } \\
\text { online review comments along the } \\
\text { spectrum of product popularity. }\end{array}$ \\
\hline
\end{tabular}




\section{Appendix B: Items for measuring the dimensions of review helpfulness}

\section{Table B1. Items for measuring dimension of review helpfulness}

Perceived source credibility (source: [16])

1. I perceive that the reviewer is reputable.

2. I perceive that the reviewer is good.

3. I perceive that the reviewer is trustworthy.

Perceived content diagnosticity (source:[39])

1. The reviews helped me familiarize myself with the product.

2. The reviews helped me evaluate the product.

3. The reviews helped me understand the performance of the product.

Perceived vicarious expression (source: [49])

1. By reading this product review, I can feel what the author is trying to say about the product and his/her usage experience.

2. By reading this product review, I can imagine what the author is trying to say about the product and his/her usage experience.

3. By reading this product review, I can envision what the author is trying to say about the product and his/her usage experience. 